\title{
Evaluations and Selections for High Isoflavone Black Soybean Mutants Induced by $\mathrm{NaN}_{3}$ Treatment
}

\author{
Toong Long Jeng ${ }^{1}$, Yi Ju Shih ${ }^{1}$, Min Tze Wu ${ }^{1}$, Chiang Sheng Wang ${ }^{2}$ Jih Min Sung ${ }^{3 *}$ \\ ${ }^{1}$ Biotechnology Division, Agricultural Research Institute, Taichung County, Taiwan; ${ }^{2}$ Department of Agronomy, National Chung \\ Hsing University, Taichung, Taiwan; ${ }^{3}$ Department of Food Science and Technology, Hung Kuang University, Taichung County, \\ Taiwan. \\ Email: ${ }^{*}$ sungjm@sunrise.hk.edu.tw
}

Received April 12 ${ }^{\text {th }}, 2013$; May 13 ${ }^{\text {th }}, 2013$; accepted June 11 $1^{\text {th }}, 2013$

Copyright (C) 2013 Toong Long Jeng et al. This is an open access article distributed under the Creative Commons Attribution License, which permits unrestricted use, distribution, and reproduction in any medium, provided the original work is properly cited.

\begin{abstract}
Sodium azide $\left(\mathrm{NaN}_{3}\right)(2 \mathrm{mM})$ was used to induce mutation in black soybean variety CRWD for improvement of isoflavone content. The individual selections were made in M6, M7 and M8 generations, respectively. Both high levels of isoflavones and medium seed size traits were used as selection criteria. Across three growth seasons, the selected five $\mathrm{NaN}_{3}$-induced mutants accumulated more total isoflavones (average increases of $5 \%$ to $25 \%$ ) than their wild type variety CRWD. Four mutants yielded more (average increases of $17 \%$ to $25 \%$ ) than CRWD. Both mutants SA-M-03 (yellow cotyledon) and SA-M-05 (green cotyledon) are rich in isoflavones and may be useful in food and other applications.
\end{abstract}

Keywords: Black Soybean; Isoflavones; Mutation; Sodium Azide

\section{Introduction}

Isoflavones are a subclass of flavonoids derived from the phenylpropanoid pathway [1]. They are found predominantly in black soybean (Glycine max (L.) Merrill) cotyledons, and are reported to be protective against breast and ovarian cancer, cardiovascular diseases and osteoporosis [2-4]. Isoflavones also show significant antioxidant activities by inhibiting lipid peroxidation, scavenging free radicals and promoting anti-oxidative enzymes [5]. Due to these beneficial health effects, breeding varieties with high isoflavone content has been one of essential goals in soybean improvement programs [6].

Traditional breeding methods, including parent lines selection, crossing and segregation, have been used to develop soybean lines with high isoflavone content in the seeds $[7,8]$. However, because the isoflavone content of soybean seeds is affected by environments, breeding soybean cultivars with high levels of isoflavones in the classical manner is difficult [9]. Alternatively, a desirable soybean line with high isoflavone trait might be produced through mutation breeding. A large amount of mutants have been identified as donors of desirable traits in many crop breeding programs [10,11]. Mutation

"Corresponding author. breeding of soybeans also yielded in identification of many mutant lines with desirable traits, including resistance to pod shattering habit, low linolenic content and high oleic content $[12,13]$.

Chemical mutation has been used to create and increase genetic variability in crop species, and ultimately change plant traits [10]. The main advantage of chemical mutation is the possibility of improving one or two specific characteristics without altering the rest of acceptable genotypes. Chemical mutation also has a number of inherent attractions, such as the ability to use different mutagens, change mutagen doses and scale the size of the mutagenesis procedures [14]. Sodium azide $\left(\mathrm{NaN}_{3}\right)$ is an excellent chemical mutagen, with high solubility in water and low toxicity to biological materials as compared to alkylating compounds that are usually used for mutation induction in plants. Sodium azide is known to create point mutation in the genome of plants by producing organic metabolite of azide compound, and thus producing protein in mutant plant with function different from the normal plant [15]. Many mutant crops have been produced by sodium azide treatment [16-19].

Black soybeans (Glycine max (L.) Merrill) have been widely consumed as folk medicines for hundreds of years in many Asian countries [20]. The seed coats of black 
soybean are rich in anthocyanins and proanthocyanidins, and have a considerably higher degree of anti-oxidative activity than yellow soybeans [19,21]. Black soybeans also contain large amounts of isoflavones in their cotyledons [19]. However, no breeding researches have so far focused on developing black soybeans for high content of isoflavones in their seeds. In the present study, attempts were made through the pedigree method of line selections by using $\mathrm{NaN}_{3}$-induced mutagenesis to obtain black soybean lines, which contained more isoflavones in seeds than their wild type variety CRWD.

\section{Materials and Method}

\subsection{Plant Materials and Mutagenesis}

Preliminary tests indicated that soaking the seeds of black soybean (Glycine max (L.) Merrill) variety CRWD with $2 \mathrm{mM} \mathrm{NaN}_{3}$ for $1 \mathrm{~h}$ showed no visible damages to treated seeds. Therefore, $2 \mathrm{mM} \mathrm{NaN}_{3}$ solution was used as the mutagen for mutation induction in CRWD. In the autumn of 2005, 500 CRWD seeds (M0) were soaked in $2 \mathrm{mM} \mathrm{NaN}_{3}$ solution for $1 \mathrm{~h}$ at room temperature, and were washed with distilled water.

\subsection{Field Planting and Mutantt Population Development}

One hundred and thirty $\mathrm{NaN}_{3}$-treated $\mathrm{M} 0$ seeds with uniform seed weight (about $170 \mathrm{mg} \cdot \mathrm{seed}^{-1}$ ) were randomly selected and planted in the experimental farm of Agricultural Research Institute (Wufeng, Taichung City, Taiwan). The matured seeds (M1) from each individual plant were harvested and bagged separately (130 packages in total). In the spring of 2006 , five randomly selected M1 seeds from each package were treated with 2 $\mathrm{mM} \mathrm{NaN} \mathrm{N}_{3}$ again and were sown as M1 populations (650 individuals) in the field. The matured seeds (M2) from M1 populations were harvested and bagged (650 packages) separately. In the autumn of 2006, three M2 seeds randomly selected from each package were planted in the field (1950 individuals). In the autumn of 2006, three M2 seeds from each package were randomly selected and planted in the field for the M3 generation. One thousand individual plants were randomly selected, and the matured M3 seeds harvested from these individuals were packed (1000 packages) separately. Among those harvested 1000 seed packages, 200 packages of M3 seeds that had showed higher seed yield per plant than wild type variety CRWD were selected for isoflavone analysis. These chosen seeds for isoflavone analysis were also used for seed weight determination. In the spring of 2007, top 40 progenies (50 seeds each) with high isoflavone content were selected and planted in the field. The produced M4 seeds were harvested, weighed and packed
(2000 packages) separately. One hundred and twenty M4 seed packages were selected for isoflavone analysis. Among these, nine lines with high isoflavone content were selected and planted (each with 50 plants) in the autumn of 2007. Finally, five lines were selected and planted (each with 50 plants) in spring and autumn of 2008 for seed yield and isoflavones content comparisons.

\subsection{Isoflavones Determination}

The content of isoflavones was determined using the methods of Kim et al. [22] with some modifications. Seed materials were extracted with $0.12 \mathrm{~N} \mathrm{HCl}$ (in methanol) for $24 \mathrm{~h}$ at $4^{\circ} \mathrm{C}$ under dark condition. The extract $(5 \mathrm{ml})$ was acidified with $2.5 \mathrm{ml} 2.4 \mathrm{~N} \mathrm{HCl}$ at $100^{\circ} \mathrm{C}$ for $40 \mathrm{~min}$, filtered through a Whatman no. 42 filter paper. The filtrate was dried in a vacuum rotary evaporator at a temperature below $30^{\circ} \mathrm{C}$ and then re-dissolved in high performance liquid chromatography (HPLC)-grade methanol. The re-dissolved sample was filtered through a $0.45 \mu \mathrm{m}$ filter unit (Cameo 13N syringe-filter, nylon). The concentrated extract was analyzed using a HPLC (Waters 2696, USA) with ODS column (Inertsil ODS-3 column, $4.6 \times 250 \mathrm{~mm}, 5 \mu \mathrm{m}$, Japan). A linear HPLC gradient was used with solvent A $(0.5 \%$ phosphoric acid in distilled water) and solvent B (acetonitrile). The solvent flow rate was $1 \mathrm{ml} \cdot \mathrm{min}^{-1}$. The wavelength of the photodiode array detector was set at $256 \mathrm{~nm}$. The linear standard calibration curves were generated by injecting 0.05 to $1 \mu \mathrm{g}$ of purified daidzein, genistein, glycitien, genistin, daidzin, glycitin, acetylgenistein, acetyldaidzin, acetylglycitin, malonylgenistin, malonyldaidzin, malonlyglycitin (Wako, Japan) in $20 \mu$ l of diluted $0.12 \mathrm{~N}$ $\mathrm{HCl}$ (in methanol).

\subsection{Yield Trial}

For yield comparisons, all the selected black soybean lines were grown in the experiment farm of Agriculture Research Institute of Taiwan (Wufeng, Taichung, Taiwan). The experimental design was a randomized complete block design with three replicates. The experimental plots for yield trial consisted of two 7-m long rows. The spacing was $0.6 \mathrm{~m}$ between rows and $0.15 \mathrm{~m}$ between plants within rows. Fertilization consisted of a banded application of $16 \mathrm{~kg} \mathrm{~N}, 32 \mathrm{~kg} \mathrm{P}_{2} \mathrm{O}_{5}$ and $31 \mathrm{~kg}$ $\mathrm{K}_{2} \mathrm{O} \mathrm{ha}^{-1}$. The central $5 \mathrm{~m}$ area of each plot was harvested to estimate seed yield per plant and seed yield components (number of pods per plant, number of seeds per pod and 100 -seed weight).

\subsection{Statistical Analysis}

All the agronomic traits data for selected $\mathrm{NaN}_{3}$-induced mutants were expressed as mean \pm standard deviation (n 
$=3$ ). The agronomic data were subjected to an analysis of variance. When a significant $(\mathrm{P}<0.05) \mathrm{F}$ ratio occurred for treatment effects, a least significant difference (LSD) was calculated. Correlation analysis was used to characterize the relationships between seed weight and isoflavone content for selected M4 seeds population.

\section{Results and Discussion}

\subsection{Selection of Mutants}

Assessing the potential of progenies at early stages of selection or screening is important in the improvement of autogamous species, because it eliminates the progenies with low potential for the traits of interest and focus on the potentially best progenies. Therefore, in this study, throughout the growth seasons, the M1 to M3 generations were repeatedly evaluated for phenotypes distinctive from the wild type CRWD. Considerably phenotypic changes, such as changes in leaf shape, delaying in maturity, changes in canopy structure and the development of leaf rust, were detectable among the M1 generation (data not presented). Similar phenotypic changes were also reported in rice [17] and common bean mutants [19] induced by $\mathrm{NaN}_{3}$ treatments. These results re-confirmed that $\mathrm{NaN}_{3}$ is a very powerful and efficient chemical mutagen [15].

As shown in Figure 1(a), great variation for total isoflavone content existed in the produced M4 mutants (Figure 1(a)). The frequency distribution of the selected mutants for total isoflavone content, on the basis of M4 seeds analysis, departed from normality. The highest frequency of mutants was in the category of 2.0 to 2.5 $\mathrm{mg}$ total isoflavone content per $\mathrm{g}$ seed dry weight, with the peak skewed toward left (Figure 1(a)). The isoflavone content in wild type variety CRWD was also in this category. Nevertheless, several mutants did have the total isoflavone content in the category of 3.0 to $4.0 \mathrm{mg}$ per seed dry weight. These results were higher than the value of the isoflavone content ( $0.85 \mathrm{mg}$ per seed dry weight) reported by Seguin et al. [23].

The seed weight distribution of selected $200 \mathrm{M} 4 \mathrm{mu}-$ tants was recorded and presented in Figure 1(b). The frequency distribution of the seed weight also departed from normality. The highest frequency of mutants was found in the seed weight category of 195 to $210 \mathrm{mg}$, and the peak was also skewed toward the right. It appeared that the $\mathrm{NaN}_{3}$-induced mutation also tends to increase seed mass among the tested mutant lines.

As shown in Figure 2, total isoflavone content in the tested M3 seeds was negatively correlated with seed dry weight $(\mathrm{r}=-0.33, P<0.01)$. This result differs from the report of Seguin et al. [23] in that a weak but significant positive correlation between total isoflavone content and seed weight $(\mathrm{r}=0.17, P<0.01)$ was found in seeds of

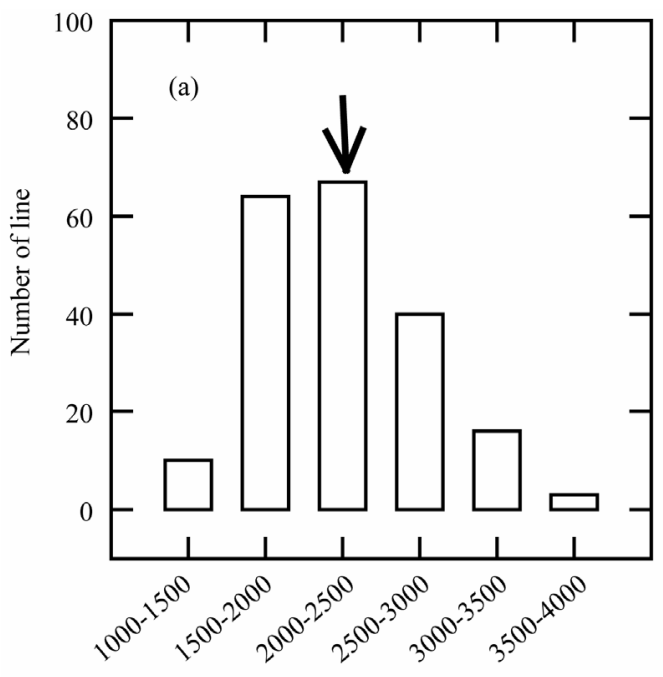

Total isoflavone content $(\mu \mathrm{g} / \mathrm{g}$ seed $)$

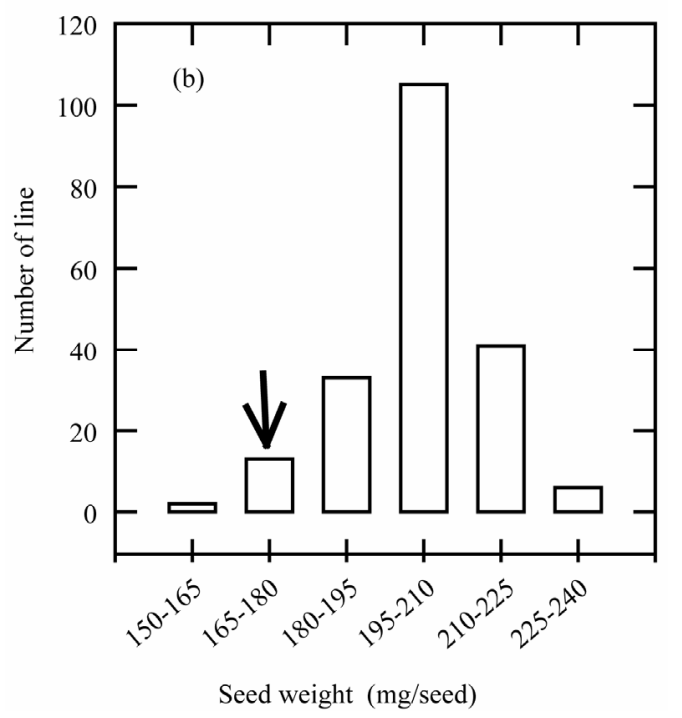

Figure 1. Distribution of total isoflavone content (a) and seed weight (b) in M3 seeds of 200 black soybean entries. Arrows indicate the total isoflavone and seed weight of wild type variety CRWD.

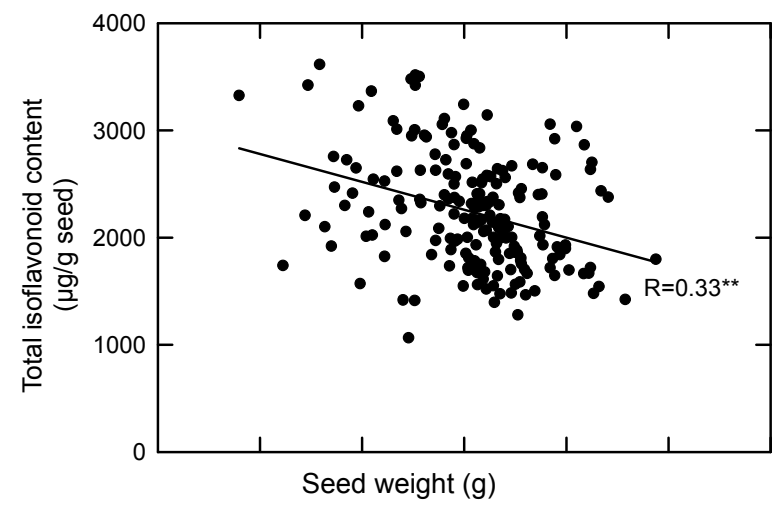

Figure 2. Regression analysis between total isoflavone content and seed weight for the M4 seeds of 200 black soybean entries. 
soybean cultivars grown in eastern Canada. The negative correlation between seed total isoflavone content and seed dry weight suggests that the seed weight (relatively lower seed weight) might be useful as an indirect morphological marker for selecting isoflavone-rich mutants. In this regard, both seed weight and total isoflavone content were determined and utilized for selecting high seedisoflavone mutants in M5 generation. Seed dry weight is an important factor involved in soybean yield determination [24]. Therefore, the cut-offs for selected seed weight was established in the range of 200 and $220 \mathrm{mg}$ per seed. Only the mutants with seed weight within this range were selected to make sure that the selected mutated lines would have a desirable seed yield.

Growing environment has been reported to have a greater effect on total isoflavone content [25]. Thus, breeders selecting genotypes with high levels of isoflavones will have to grow their breeding materials across multiple years. In this study, the isoflavone-rich seed selections in M5 generations were continued using the similar approach applied to the M4 generation. In the M4 generation, several mutant lines with total isoflavone content in the range of 3.30 to $3.80 \mathrm{mg}$ per g seed dry weight were encountered (Figure 3). However, the total isoflavone content in the M5 generation were decreased considerably. This was possibly due to the relatively higher air temperature during seed-fill stages in the 2007 spring crop season than that in 2007 autumn crop season (data not presented). The report of Tsukamoto et al. [25] also confirmed that isoflavone content was significant lower in the soybean seeds that were grown under hightemperature conditions.

\subsection{Yield Comparison}

The combined analyses of variance for seed dry weight, isoflavones content and yield per plant of selected mutants and wild type variety CRWD grown in 2007 autuman (M5), 2008 spring (M6) and 2008 autumn (M7) were shown in Table 1. Crop season, variety and crop season $\mathrm{x}$ variety were found to have significant effects on seed dry weight (Table 1). Marked change in cotyledon color was also found for selected mutants SA-M-01, SA-M-02 and SA-M-03, in that a yellow cotyledon color was detect in these mutants compared with green cotyledon color of wild type CRWD (Table 2). Nevertheless, the green cotyledon was found for SA-M-04 and SA$\mathrm{M}-05$. These results are not unexpected because chemical mutagenesis is known to generate a large number of variants in any genotypes [11,19].

Significant crop season, variety and crop season $\times$ variety effects on isoflavones content (Table 1). In general, the mutants grown under 2008 spring having lower total isoflavones content than the mutants grown in 2007 au- tumn and 2008 autumn (Table 2). Despite the crop season influences, across all crop seasons, the selected mutants generally expressed higher total isoflavones than wild type CRWD. The lowest increase (average across three generations) was found for mutants SA-M-04 (with green cotyledon).

As shown in Table 1, only crop season and crop season $\times$ variety were found to have significant effects on seed yield plant ${ }^{-1}$ (Table 1). The highest yield increase was obtained from mutant SA-M-05 (with an average of $25 \%$ increase across three growing seasons), and then followed by mutants SA-M-04 (24\% increase), SA-M-02 (17\% increase), SA-M-03 (16\% increase) and SA-M-01 ( $4 \%$ increase), in comparison with wild type variety CRWD (Table 2). Based on the isoflavone content and yield data, it was concluded that mutants SA-M-03 and SA-M-05 are useful in food and other applications.

\section{Conclusion}

Our results indicate that, after a chemical treatment with the mutagen sodium azide $\left(\mathrm{NaN}_{3}\right)(2 \mathrm{mM})$, it is possible to generate genetic variability in the isoflavone content in black soybean seeds. From the progeny of the mutated black soybean variety CRWD seeds, two mutants (SA-M-03 and SA-M-05) with high isoflavone content and relatively high yield potential are selected. It appears that these two mutants, SA-M-03 with yellow cotyledon and SA-M-05 with green cotyledon, are enriched with isoflavones, and may be useful in black soy-

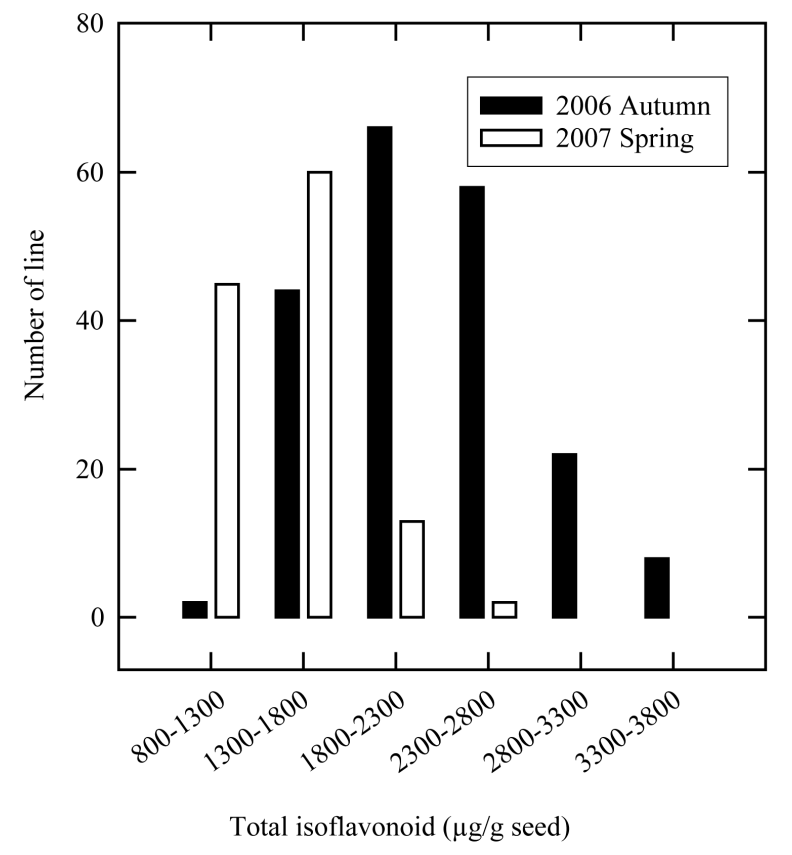

Figure 3. Distribution of total isoflavone content in M3 (autumn of 2006) and M4 (spring of 2007) seeds of black soybean entries. 
Table 1. Analysis of variance for seed dry weight, isoflavones content and yield per plant of selected $\mathrm{NaN}_{3}$-induced black soybean mutants.

\begin{tabular}{lccc}
\hline Source of variation & DF & MSE Seed dry weight & MSE Isoflavones content $^{\text {MSE Yield plant }^{-1}}$ \\
\hline Season & 2 & $1504^{* *}$ & $11482047^{* *}$ \\
Block & 6 & $59^{*}$ & 33925 \\
Variety & 5 & $114^{* *}$ & $0.00727857^{* *}$ \\
Season x Variety & 10 & $113^{* *}$ & 0.00032385 \\
Error & 30 & 20 & $0.00036862^{*}$ \\
\hline
\end{tabular}

*** significant at $\mathrm{P}<0.01,{ }^{*}$ significant at $\mathrm{P}<0.05$.

Table 2. Several agronomic traits of selected $\mathrm{NaN}_{3}$-induced black soybean mutants.

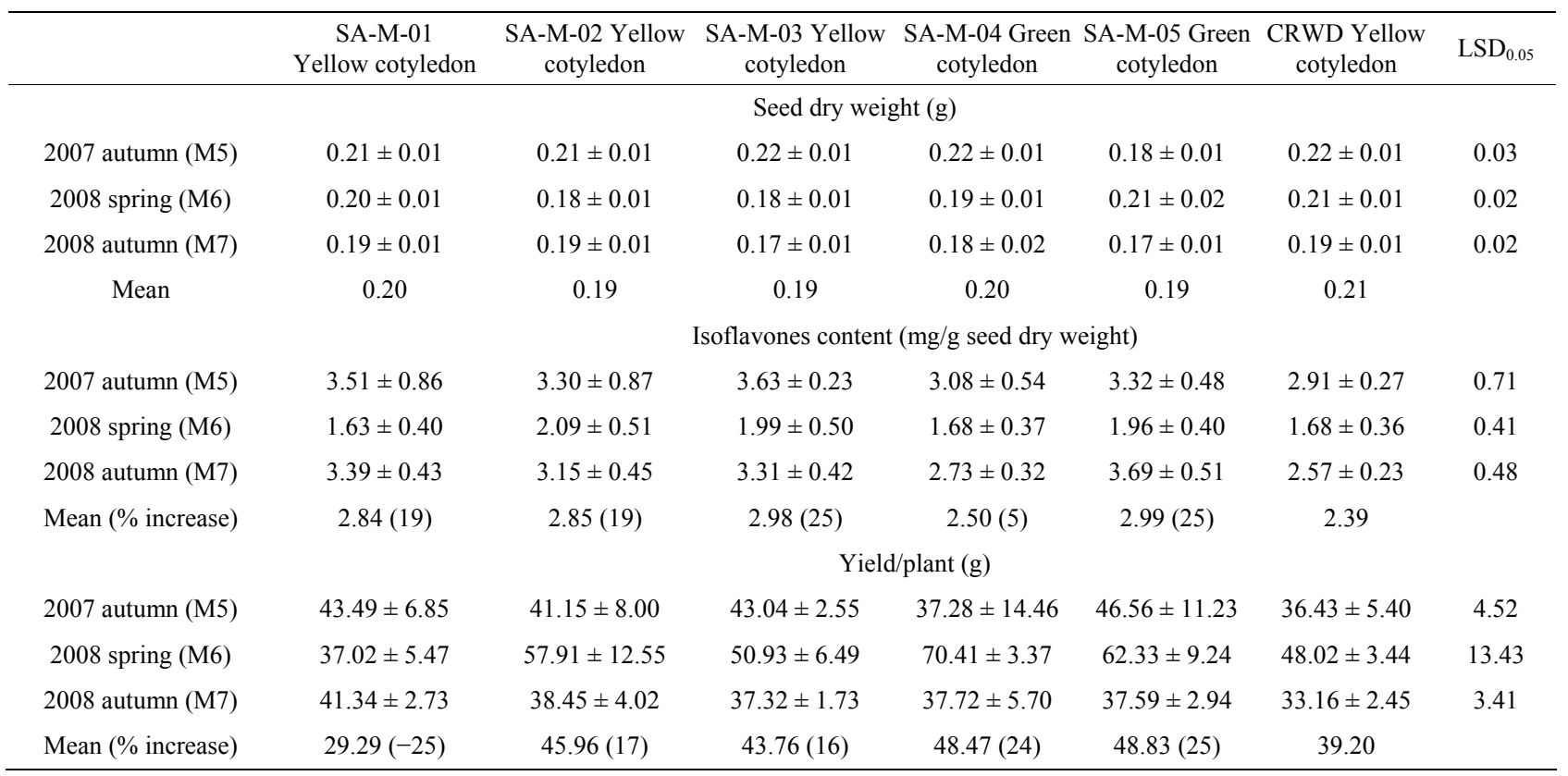

bean breeding programs and other functional food applications.

\section{REFERENCES}

[1] B. Winkel-Shirley, "Flavonoid Biosynthesis, a Colorful Model for Genetics, Biochemistry, Cell Biology, and Biotechnology," Plant Physiology, Vol. 126, No. 2, 2001, pp. 485-493. doi:10.1104/pp.126.2.485

[2] T. Izumi, M. K. Piskula, O. Osawa, A. Obata, K. Tobe, M. Saito, S. Kataoka, Y. Kubota and M. Kikuchi, "Soy Isoflavone Aglycones Are Absorbed Faster and in Higher Amounts than Their Glucosides in Humans," Journal of Nutrition, Vol. 130, 2000, pp. 1695-1699.

[3] C. H. Lee, L. Yang, J. Z. Xu, S. Y. V. Yeung, Y. Huang and Z.-Y. Chen, "Relative Antioxidant Activity of Soybean Isoflavones and Their Glycosides," Food Chemistry, Vol. 90, No. 4, 2005, pp. 735-741. doi:10.1016/j.foodchem.2004.04.034

[4] M. Messina, W. McCaskill-Stevens and J. W. Lampe, "Addressing the Soy and Breast Cancer Relationship: Re- view, Commentary, and Workshop Proceedings," Journal of the National Cancer Institute, Vol. 98, No. 18, 2006, pp. 1275-1284. doi:10.1093/jnci/djj356

[5] K. D. R. Setchell, "Phytoestrogens: The Biochemistry, Physiology, and Implications for Human Health of Soybean Isoflavones," American Journal of Clinical Nutrition, Vol. 68, No. 6, 1998, pp. 1333S-1346S.

[6] M. J. Morrison, E. R. Cober, M. F. Saleem, N. B. McLaughlin, J. Frégeau-Reid, B. L. Ma, W. Yan and L. Woodrow, "Changes in Isoflavone Concentration with 58 Years of Genetic Improvement of Short-Season Soybean Cultivars in Canada," Crop Science, Vol. 48, No. 6, 2008, pp. 2201-2208. doi:10.2135/cropsci2008.01.0023

[7] L. Chiare, N. D. Piovesan, L. K. Naoe, C. José, J. M. S. Viana, M. A. Moreira, M.A. and E. G. de Barros, "Genetic Parameters Relating Isoflavone and Protein Content in Soybean Seeds," Euphytica, Vol. 138, No. 1, 2004, pp. 55-60. doi:10.1023/B:EUPH.0000047060.03101.4a

[8] V. S. Primomo, V. Poysa, G. R. Ablett and C.-J. Jackson, "Agronomic Performance of Recombinant Inbred Line Populations Segregating for Isoflavones Content in Soy- 
bean Seeds," Crop Science, Vol. 45, No. 6, 2005, pp. 2203-2211. doi:10.2135/cropsci2004.0610

[9] J. A. Hoeck, W. R. Fehr, P. A. Murphy and G. A. Welke, "Influence of Genotype and Environment on Isoflavone Contents of Soybean," Crop Science, Vol. 40, No. 1, 2000, pp. 48-51. doi:10.2135/cropsci2000.40148x

[10] B. S. Ahloowalia and M. Maluszynski, "Induced Mutations: A New Paradigm in Plant Breeding," Euphytica, Vol. 118, No. 2, 2001, pp. 167-173. doi:10.1023/A: 1004162323428

[11] B. S. Ahloowalia, M. Maluszynski and K. Nichterlein, "Global Impact of Mutation-Derived Varieties," Euphytica, Vol. 135, No. 2, 2004, pp. 187-204. doi:10.1023/B:EUPH.0000014914.85465.4f

[12] S. M. Rahman, V. Takagi, K. Kubota, K. Miyamoto and V. Kawakita, "The High Oleic Acid Mutant in Soybean Induced by X-Rays Irradiation," Bioscience, Biotechnology, and Biochemistry, Vol. 58, No. 6, 1994, pp, 10701072.

[13] S. M. Rahman, V. Takagi, K. Kubota, K. Miyamoto and V. Kawakita, "High Stearic Acid Soybean Mutant Induced by X-Ray Irradiation,” Bioscience, Biotechnology, and Biochemistry, Vol. 59, No. 5, 1995, pp. 922-933. doi:10.1271/bbb.59.922

[14] D. G. Caldwell, N. McCallum, P. Shaw, G. J. Muehlbauer, D. F. Marshall and R. Waugh, "A Structured Mutant Population for Forward and Reverse Genetics in Barley (Horedeum vulgare L.)," The Plant Journal, Vol. 40, No. 1, 2004, pp. 143-160. doi:10.1111/j.1365-313X.2004.02190.x

[15] F. Al-Queainy and S. Khan, "Mutagenic Effects of Sodium Azide and Its Application in Crop Improvement," World Applied Sciences Journal, Vol. 6, No. 12, 2009, pp. 1589-1601.

[16] V. Fernández-Moya, E. Martínez-Force and R. Garcés, "Temperature Effect on a High Stearic Acid Sunflower Mutant," Phytochemistry, Vol. 59, No. 1, 2002, pp. 33-37. doi:10.1016/S0031-9422(01)00406-X

[17] T. L. Jeng, S. H. Tseng, C. S. Wang, C. L. Chen and J. M. Sung, "Starch Biosynthesizing Enzymes in Developing Grains of Rice Cultivar Tainung 67 and Its Sodium Azide -Induced Rice Mutant," Field Crops Research, Vol. 84, No. 3, 2003, pp. 261-269. doi:10.1016/S0378-4290(03)00094-7
[18] J. K. Mensah and B. Obadoni, "Effects of Sodium Azide on Yield Parameters of Groundnut (Arachis hypogaea L.)," African Journal of Biotechnology, Vol. 6, No. 6, 2007, pp. 668-671.

[19] T. L. Jeng, Y. J. Shih, C. C. Lai, M. T. Wu and J. M. Sung, "Anti-Oxidative Characterization of NaN3-Induced Common Bean Mutants," Food Chemistry, Vol. 119, No. 3, 2010, pp. 1006-1011. doi:10.1016/j.foodchem.2009.08.001

[20] B. J. Xu and S. K. C. Chang, "Antioxidant Capacity of Seed Coat, Dehulled Bean, and Whole Black Soybeans in Relation to Their Distributions of Total Phenolics, Phenolic Acids, Anthocyanins, and Isoflavones," Journal of Agricultural and Food Chemistry, Vol. 56, No. 18, 2008, pp. 8365-8373. doi:10.1021/jf801196d

[21] J.-A.Kim, S.-B. Hong, W.-S. Jung, C.-Y. Yu, K.-H. Ma, J.-G. Gwag and I.-M Chung, "Comparison of Isoflavones Composition in Seed, Embryo, Cotyledon and Seed Coat of Cook-With Rice and Vegetable Soybean," Food Chemistry, Vol. 102, No. 3, 2007, pp. 738-744. doi:10.1016/j.foodchem.2006.06.061

[22] S. H. Kim, W. S. Jung, J. K. Ahn and I. M. Chung, “Analysis of Isoflavone Concentration and Composition in Soybean [Glycine max (L.)] Seeds between the Cropping Year and Storage for 3 Years" European Food Research and Technology, Vol. 220, No. 2, 2005, pp. 207-214. doi:10.1007/s00217-004-1048-5

[23] P. Seguin, W. Zhang, D. L. Smith and W. Deng, "Isoflavone Content of Soybean Cultivars Grown in Eastern Canada," Journal of the Science of Food and Agriculture, Vol. 84, No. 11, 2004, pp. 1327-1332. doi: $10.1002 /$ jsfa. 1825

[24] P. A. Calviño, V. O. Sadras and F. H. Andrade, "Development, Growth and Yield of Late-Sown Soybean in the Southern Pampas," European Journal of Agronomy, Vol. 19, No. 2, 2003. pp. 265-275. doi:10.1016/S1161-0301(02)00050-3

[25] C. Tsukamoto, S. Shimada, K. Igita, S. Kudou, K. Koubun, K. Okubo and K. Kitamura, "Factors Affecting Isoflavone Content in Soybean Seeds: Changes in Isoflavones, Saponins, and Composition of Fatty Acids at Different Temperature during Seed Development," Journal of Agricultural and Food Chemistry, Vol. 43, No. 5, 1995, pp. 1184-1192. doi:10.1021/jf00053a012 